\title{
Isotype-specific Changes in the Amount of $\beta$-Tubulin RNA in Synchronized Tobacco BY2 Cells
}

\author{
Shoji Okamura*, Koichi Okahara, Takayuki Iida, Miwa Ozaki, Sayaka Asano, Masashi Morita, \\ and Tsuneo Imanaka \\ Faculty of Pharmaceutical Sciences, Toyama Medical and Pharmaceutical University, Toyama 930-0194, Japan
}

\begin{abstract}
$A B S T R A C T$. The $3^{\prime}$-ends of the $\beta$-tubulin cDNA were amplified from tobacco BY2 polyA ${ }^{+}$RNA. According to the differences in the predicted amino acid sequence at the extreme C-terminal, they were grouped into three different isotypes, NTB1 in which "EEGDYYEEDEEDLNEA", NTB2 in which "EEEYYEDEEEA QED" and NTB3 in which "DECEYEEEEEYDHEGN" follows the conservative "YQQYQDATAD" sequence. Using unique 3 -untranslated regions as probes, changes in the RNA levels of each $\beta$-tubulin isotype were determined by dot-blot hybridization. The levels exhibited characteristic rhythms in the cell cycle. NTB1 RNA was highest in S phase in comparison to NTB2 RNA level which was highest in late G2. On the other hand, NTB3 RNA level was highest in early G2.
\end{abstract}

Key words: $\beta$-tubulin isotypes/cell cycle/RNA level/tobacco BY2

$\mathrm{E}$ ver since DNA sequencing has been applied to determine the amino acid sequence of tubulin molecules, the genetic heterogeneity of tubulin has been noticed and its significance in the regulation and/or the function of microtubules has been discussed frequently $(3,4,6,11,19,20)$.

Unique distributions and functions of microtubules are known in plant cells during cell cycle progression and morphological differentiation (10). In tobacco BY2 cells, microtubules are formed as preprophase band at $\mathrm{G} 2$, phragmoplast at G1, and cortical microtubules at interphase, in addition to universally observed microtubules as mitotic spindles and interphase cytoplasmic microtubules extending from near the surface of the nucleus to the cell periphery (8). On the other hand, aster, midbody and centriole microtubules, observed in animal, are generally not seen in plant cells.

\footnotetext{
* To whom correspondence should be addressed: Faculty of Pharmaceutical Sciences, Toyama Medical and Pharmaceutical University, 2630 Sugitani, Toyama 930-0194, Japan.

Tel: +81-764-34-2281 (ext. 2637), Fax: +81-764-34-4656

E-mail: okamura@ms.toyama-mpu.ac.jp

The nucleotide sequences reported in this paper has been submitted to GenBank/EMBL/DDBJ with accession numbers, U91562 (NTB1), U91563 (NTB2), U91564 (NTB3).

Abbreviations: DEPC, diethyl pyrocarbonate; FITC, fluorescein isothiocyanate; PCR, polymerase chain reaction; $3^{\prime}$-RACE, rapid amplification of 3 '-cDNA ends.
}

We have reported previously that in tobacco BY2 synchronous culture, the acidic "isoform" of $\beta$-tubulin (heterogeneity of $\beta$-tubulin molecules detected by IEFimmunoblotting) increased before mitosis, and that the main isoform component shifted to a more basic one after mitosis (15). This suggests differential changes in the level of "isotypes" (heterogeneity at the genetic level) and/or their specific modifications taking place in the BY2 cell cycle. Previously, we could detect no obvious changes in the overall transcript level during the cell cycle of synchronized BY2 cells using carrot $\beta 1$-tubulin cDNA as a probe. Here, we report that when the specific $3^{\prime}$-UTR sequences were used as probes, characteristic rhythms in each isotype RNA level were observed during the cell cycle of BY2 cells.

\section{Materials and Methods}

\section{Materials}

The tobacco cell line BY2 (13) was maintained by transferring aliquots every week to fresh Murashige and Skoog's medium (12).

\section{Synchronization}

Cells were synchronized by the method of Nagata et al. (14). Ten milliliters of tobacco BY2 cell suspension which was at 
the second day of the stationary phase was added to $90 \mathrm{ml}$ of the fresh medium containing aphidicolin $(5 \mu \mathrm{g} / \mathrm{ml}$ in final) and incubated at $26^{\circ} \mathrm{C}$ for 24 hours. After the treatment with the drug, cells were washed quickly with 1 liter of the fresh medium on a sintered glass filter. The cells were then suspended in $100 \mathrm{ml}$ of fresh medium and cultured at $26^{\circ} \mathrm{C}$.

\section{Preparation of total and poly $A^{+} R N A$}

The BY2 cells collected by filtration were frozen quickly in liquid nitrogen and ground with mortar and pestle with 1 $\mathrm{ml} / \mathrm{g}$ cells each of frozen phenol and extraction buffer $(50 \mathrm{mM}$ Tris, $1 \% \mathrm{SDS}, \mathrm{pH} 9.0$ ). After thawing with an additional 1 $\mathrm{ml} / \mathrm{g}$ cells each of phenol and extraction buffer, RNA was extracted by phenol and chloroform treatment and precipitated by adding two volumes of ethanol in the presence of $0.1 \mathrm{M}$ $\mathrm{LiCl}$ ( $\mathrm{pH}$ 6.5). The precipitate was resuspended in diethyl pyrocarbonate (DEPC)-treated water and reprecipitated under $2 \mathrm{M} \mathrm{LiCl}$ overnight. The precipitated RNA was rinsed with $80 \%$ EtOH and used for Northern and dot blot analysis after the treatment of RNase-free DNaseI. For the preparation of cDNA, polyA ${ }^{+}$RNA was prepared with oligo-dT cellulose column.

\section{Construction of cDNA libraries}

Complementary DNA library was constructed as described before (17) from the polyA ${ }^{+}$RNA isolated from the cultured BY 2 cells. Double stranded cDNA synthesized by the method of Gubler and Hoffman (7) was inserted into EcoRI site of $\lambda$ gt 11 . The library was screened with the probe C- $\beta 1.8$ which is a $1.2 \mathrm{kbp}$ fragment of carrot $\beta-1$ tubulin DNA (18).

\section{Rapid amplification of 3 -cDNA ends (3'-RACE) of tobacco $\beta$-tubulin isotypes}

Amplification of $3{ }^{\prime}$-end of $\beta$-tubulin mRNAs was conducted by polymerase chain reaction (PCR) with upstream $\beta$-tubulin specific primers TB1A, 5'CTTGACAGCCTCTGCTATGTT $\mathrm{CAGG}^{\prime}$ and downstream adapter primer, AP20, 5'GGCCA CGCGTCGACTAGTAC3' using CDNA template made by reverse transcription of BY2 polyA ${ }^{+}$RNA with AP20-oligo dT as a primer (Fig. 1).

\section{Northern hybridization}

The total RNA was electrophoresed on a formalin agarose gel and transferred downward to a Hybond $\mathrm{N}^{+}$membrane with $0.4 \mathrm{~N} \mathrm{NaOH}$ for 2 hours. The membrane was washed once with DEPC-treated $2 \times \mathrm{SSPE}(1 \times \mathrm{SSPE}=150 \mathrm{mM} \mathrm{NaCl}, 10$ mM sodium phosphate, 1 mM EDTA ( $\mathrm{pH} 7.4)$ ) and used for hybridization. Hybridization was performed using probes labeled with fluorescein isothiocyanate (FITC) with Gene Images nucleic acid labeling and detection systems (Amersham, Buckinghamshire, UK). The filter was incubated with $10 \mathrm{ng}$ probe $\mathrm{DNA} / \mathrm{ml}$ prehybridization $\mathrm{mix}$ at $60^{\circ} \mathrm{C}$ overnight. $\mathrm{NaCl}$ concentration in the prehybridization mix was

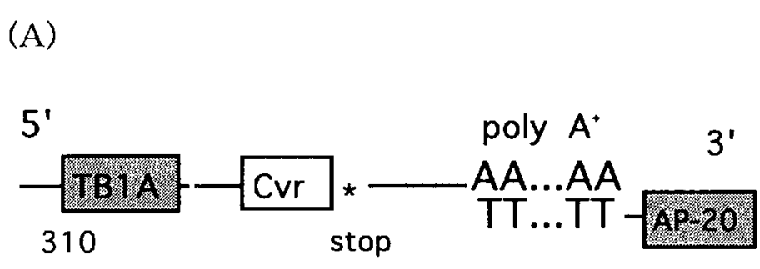

Cvr: C-terminal variable amino acid-coding region

(B)

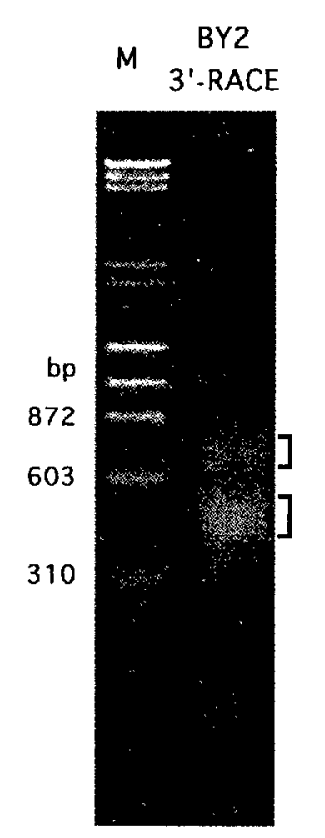

Fig. 1. 3'-RACE product on BY2 cDNA. (A) Schematic representation of $3^{\prime}$ RACE of tobacco $\beta$-tubulin. The BY 2 cDNA was made from exponentially growing BY2 cell polyA ${ }^{+}$RNA by reverse transcription with oligis-dT conjugated with an adapter-primer (AP20). (B) Agarose gel electrophoresis of the PCR product with AP20 and TB1A primer. Marker; $\lambda /$ HindIII digest and $\phi \mathrm{X} 174 /$ HaeIII digest DNA.

adjusted to $0.5 \mathrm{M}$. The filter was washed twice in $1 \times$ SSPE, $0.1 \%$ SDS and $0.5 \times$ SSPE, $0.1 \%$ SDS at $60^{\circ} \mathrm{C}$. Hybridized probes were detested with alkaline phosphatase-labeled antiFITC antibody and detected with CDP-Star and Kodak XOmat AR X-ray itlm.

\section{Dot-blot hybriclization}

Dilution series of total RNA was prepared and dotted on the Hybond $\mathrm{N}^{+}$mer:ubrane, fixed with $0.4 \mathrm{~N} \mathrm{NaOH}$ for 5 minutes and processed as in the case of Northern hybridization. The optical density (OD) of the developed X-ray film was measured and arlalyzed with BioRad Fluor-S Multi-Imager and Molecular Inıager Systems. 


\section{Results}

Cloning of a tobacco $\beta$-tubulin $c D N A$ and the amplification of $3^{\prime}$-ends of the isotype cDNAs

By screening the BY2 cDNA library with carrot $\beta 1$-tubulin DNA as a probe, we first isolated a clone containing a fragment of $\beta$-tubulin gene. The fragment was corresponding to the coding region for 227th to 332nd amino acids of typical $\beta$-tubulin. Within the sequence, a relatively conservative region, TB1A (Fig. 1(A)) was selected by comparing various $\beta$-tubulins in the database. Using these sequences and an adaptor primer AP20, we amplified the 3 -terminal region of $\beta$-tubulin genes by PCR with the cDNA made by reverse transcription of BY2 polyA + RNA as the template (Fig. 1(B)). We obtained 3 to 5 amplified products with different sizes around 500 to 700 base pairs. These amplified bands were excised from the gel and cloned.

\section{Isotype-specific sequence of C-terminal acidic amino} acid cluster

Figure 2 shows the base sequences of the cloned DNA

NTB1

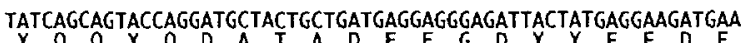
gAGgatCTTAATGAaGCTTAATTTGAATGTATGAACCAAGCACCACAATTTCCAGTTGAT GGTCCTTTGGCATTGACAACGGCAATGGAAGTAGTAGTCTTTGATAGCTATAATATGCTA TCATGTAATTTTCTTGTTAGCTTCTAAGACAATCTGCAGTATTGTAATAGTACTTGTITC TGTTGGTTGTGTTTAATCGTACITATCITGGTTITATGATGATGAAGTATTGCTCTATTA AAAAA..........AAAA

NTB2

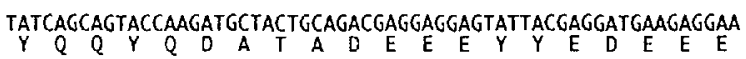
GCTCAGGAGgatTAaTTTGAAATGTGATGGTGACTTTTTAAATATGAATTAAGCCAAAAC $A Q E D *$

CACAACCTCCAGTTGATGTTCTITTGGCTGTGAGATGTAATAATACTCTTCAACTTCAG CTITTAATATCTTGTAATATITCTATTAGCTTTGGAAGACTACATGCTATGGTIATACAA GTATTATGITGCTTGTCAAAAAAA..........AAAA

NTB3

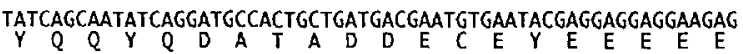
tACGATCATGAaGgCAACTGAaGAaAGaCAGATTATTATATGTGTGTATATGTTCTGATC GCCAGAGATATATAaGCAGTTTCTGTATGTTGCATCTTGCGTACACTTGCTGTGAGGTCC AGCTAGTTTTGGGCTTACGTAGTITATCAGGAGTGAATGCTGGAGAGTGAGGAGCGTGGG ITTCAAGTTGTAATACTGCTATCTGITTCTGCTTAAATATTTGTTATCTITITCTTTITG TGGTIAAAAAAA..........AAAA

Fig. 2. Nucleotide and predicted amino acid sequences of the BY2 $\beta$-tubulin isotypes. The extreme 3 -ends of NTB1-3 from the coding sequence corresponding to consensus ${ }^{422} \mathrm{YQQYQDATAD}$ to polyA ${ }^{+}$ are shown. Specific 3'-UTR probes were made by PCR using the underlined sequences as primers. and the predicted amino acids. All the clones contained polyA ${ }^{+}$at the $3^{\prime}$-end, the stop codon TAA or TGA at the appropriate place, and the variable acidic amino acid cluster at the $\mathrm{C}$-terminal coding region following the very conservative amino acid sequence, YQQYQDATAD. According to the differences in the predicted C-terminal amino acid sequences, the clones were grouped into three, and we named the three sequences NTB1, NTB2, and NTB3. Some clones contained completely the same sequence as one of the three isotypes, except that 24 or 19 nucleotides immediately before polyA ${ }^{+}$RNA were deleted from NTB1 or NTB2, respectively, suggesting that the position of the poly $\mathrm{A}^{+}$addition is flexible. There were no typical polyA $^{+}$signal, AATAAA in any of three isotype genes. The isotype specific probes were synthesized by PCR using the primers shown in Figure 2 and labeled

\section{(A) Ethidium bromide staining}
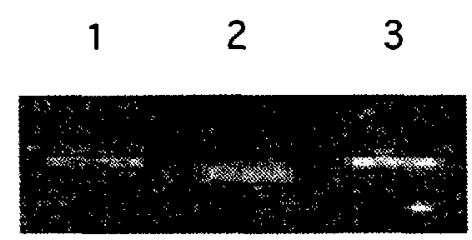

\section{(B) Hybridization}

probe

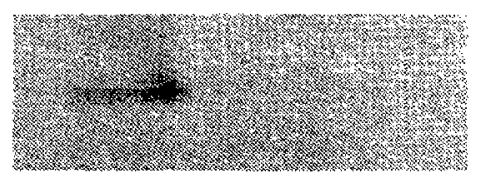

NTB1 3'-UTR

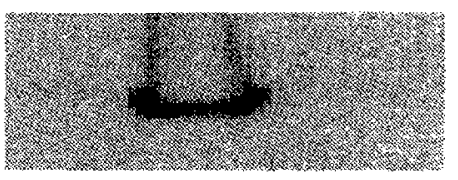

NTB2 3'-UTR

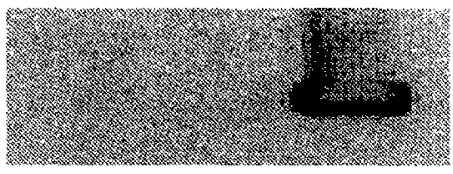

NTB3 3'-UTR

Fig. 3. Specific hybridization of each 3 -UTR probes to corresponding isotype cDNA ends. The inserts from the cloned plasmids (1: NTB1, 2: NTB2, 3: NTB3) were electrophoresed on 1.5\% agarose gel (A), blotted on a charged Nylon membrane and hybridized with each probe (B). No cross hybridization of the probes was observed among these isotypes. 
with FITC. The isotype-specificity of each probe was confirmed by Southern blot hybridization of plasmid clones (Fig. 3). Plasmids containing one of the three isotypes were purified, digested with appropriate restriction enzymes to excise inserts and electrophoresed on a $1.5 \%$ agarose gel. The probes hybridized only with the corresponding inserts of the plasmids.

\section{Hybridization assay of NTBI-3 RNA in synchronized BY2 cells}

Quantitation of the amount of each isotype RNA was performed by the dot-blot hybridization of dilution series of total RNA. In order to know the reliable range for the quantitation, dilution series of standard $\lambda$-DNA was dot-blotted on a charged Nylon membrane, hybridized with the labeled $\lambda$-DNA, processed as described in Materials and Methods and the OD of each spot on the film was measured. The OD and the amount of applied nucleic acid correlated linearly at $O D$ values up to 1.0 (Fig. 4). Dot-blot hybridization of BY2 RNA with each isotype probes were performed under the condition where no non-specific binding bands were observed by Northern blot analysis. Dilution series of the total RNA prepared from the cells every 2 hours, beginning at one hour after the release of the aphidicolin treatment, was spotted on a charged Nylon membrane and hybridized with 3 '-UTR probes specific to each isotype. The ODs of the developed Xray film were measured and plotted (Fig. 5). The density per microgram RNA in a dot was calculated from

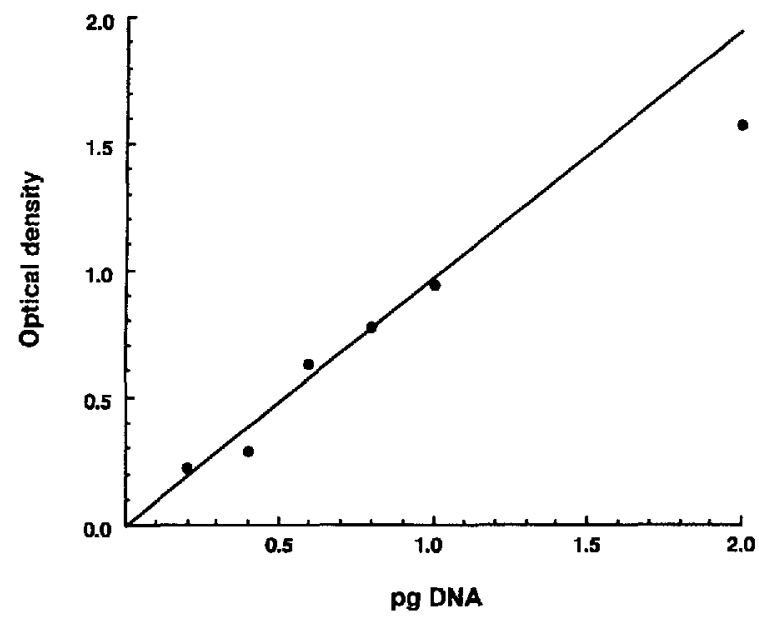

Fig. 4. Relationship between optical density of the spots and the amount of applied nucleic acid on the membrane after hybridization with non-RI detection system. Various amounts of $\lambda$-DNA were spotted on a charged Nylon membrane and hybridized with FITC-labeled $\lambda$-DNA. The hybridized DNA was detected by binding alkaline phosphatase-conjugated anti FITC-antibody, reacted with CDPStar, and exposed to Kodak X-Omat AR film. The optical density of the spots were measured and quantitated by Molecular Imager.
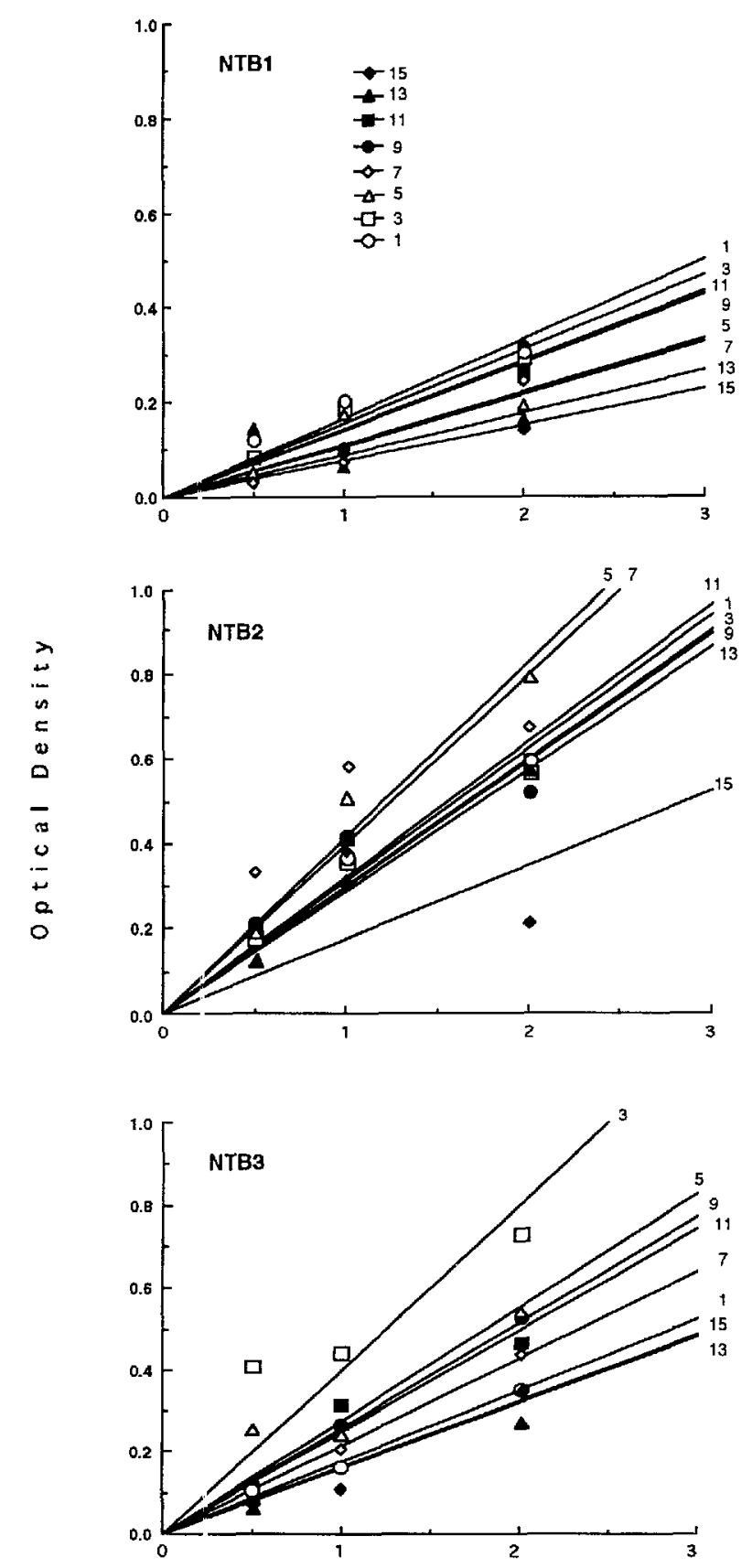

$\mu g$ RNA

Fig. 5. Dot blot hybridization of RNAs from synchronized BY2 cells. Dilution ser es of the total RNA prepared from BY2 cells at various times of the synchronous culture was spotted on a charged Nylon membrane and hybridized with 3 -UTR probes specific to NTB1, 2 or 3. The optical density of the spots on developed film was measured and ploted against the amount of applied total RNA. The regression lines were drawn after the subtraction of background. The coefficient and its : tandard error of each line were obtained and plotted in Figure 6. F.gures at the end of each regression line represent hours after the aphidicolin release. 

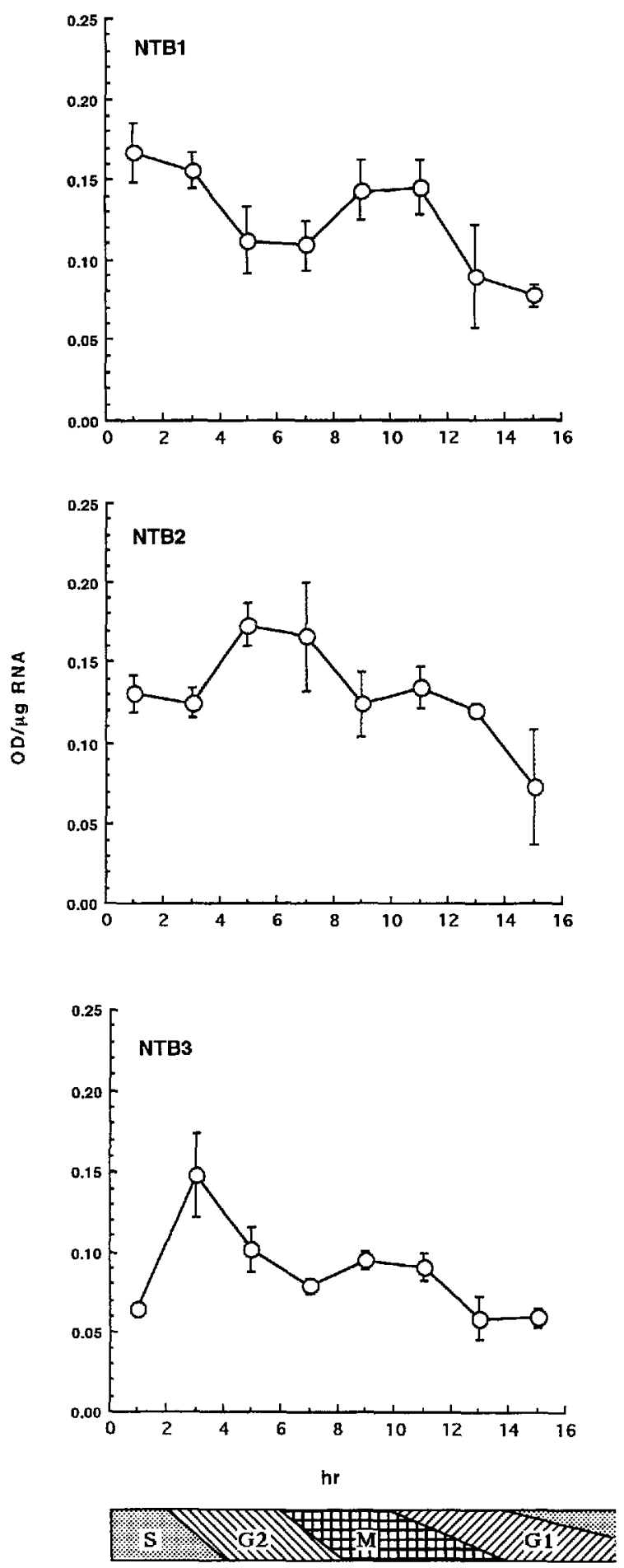

Fig. 6. Changes in the isotype RNAs in a cell cycle of BY2. The optical density per $\mu \mathrm{g}$ RNA was calculated from the values obtained in Figure 5. The values were calibrated for the difference in the labeling efficiency of the probes. The relative labeling efficiencies obtained by measuring the intensity of the FITC fluorescence of the probes, NTB1:NTB2:NTB3 were 1:2.4:2.7. Bars show standard errors. The scale below the abscissa shows the approximate cell cycle phases (15). the slopes of the regression lines in Figure 5 and the results were plotted against time after the aphidicolin release (Fig. 6). Characteristic differntial waves of the amounts of each isotype RNA were observed reproducibly in repeated experiments. The period of each cell cycle phase has been determined previously $(15$; shown at the bottom of Fig. 6). When the time course of each RNA level was followed with reference to the cell cycle period, NTB1 RNA increased first at S phase and secondly, at $M$ to early G1 phase. The NTB2 RNA increased at late G2 phase and the NTB3 RNA, at early G2.

\section{Discussion}

In the present work, we obtained and sequenced three different isotype clones of tobacco $\beta$-tubulin and prepared their unique 3'-UTR fragments as isotype-specific probes. In contrast to the relatively constant overall $\beta$-tubulin RNA content, each isotype RNA level was found to change specifically and to have different rhythms in a cell cycle. NTB1 RNA increased at S and also at $M$ to early G1 phase. NTB2 RNA increased at late G2 and NTB3 RNA increased at early G2 phase. Though it is necessary to examine the fate of the increased RNA and its product for the further interpretation of the results, the differential rhythms of the levels in the three isotype RNAs suggest their differential role in either regulation or function of microtubule arrays.

The structural differences among the isotypes are condensed in the acidic amino acid cluster at the extreme C-terminal region. The C-terminal region of the tubulin molecule is thought to be exposed to the surface of the molecule and may directly or indirectly interact with the factors that regulate the distribution or function of tubulin. Recently, the 3D structure of $\alpha$ and $\beta$-tubulin was postulated (16). According to this model, the conservative YQQYQDATAD sequence is located at the region between the extreme $\mathrm{C}$-terminal acidic amino acid cluster and the 12th helix, that is, almost parallel to the 11th helix located also at the outer surface of the microtubule wall. The 12th helix consists of strictly conservative amino acid sequence and has a highly negative charged face. It is natural to assume that the intensity of the negative charge at the extreme C-terminal domain may have some specific role in the regulation of tubulin function via interacting proteins such as MAPs (2). Besides such points of topological interest, this region is also known as being susceptible to several types of posttranslational modifications including those which bring about alterations in electrical charge $(1,5,9)$.

As we reported previously, the $\beta$-tubulin protein split into at least three isoform bands on isoelectric focus- 
ing gel and their proportions changed characteristically during cell cycling (15). The most acidic isoform increased at G2 and the most basic one increased after $\mathrm{M}$ phase. If all these isoforms are the products of the three isotype genes reported in this paper, the posttranslational modifications which cause charge alteration might take place in the cell because the net charge of the variable regions of NTB1 and NTB2 are estimated to be identical (under neutral pH, half of NTB3, which contains histidine in this region, would also be equal in charge to the others (Fig. 2)).

In conclusion, we found differential rythms in the three $\beta$-tubulin isotype RNA levels in the cell cycle of tobacco BY2 cells. Identification of the "isoforms" in the previous report in the light of the "isotypes" described in this report, examination of their distribution and survey of their interacting factors are necessary for the further elucidation of the significance of the rhythms of $\beta$-tubulin isotype and isoform levels observed in BY 2 cells.

\section{References}

1. Alexander, J.E., Hunt, D.F., Lee, M.K., Shabanowitz, J., Michel, H., Berlin, S.C., McDonald, T.L., Sundberg, R.J., Rebhun, L.H., and Frankfurter, A. 1991. Characterization of posttranslational modifications in neuron-specific class III $\beta$ tubulin by mass spectrometry. Proc. Natl. Acad. Sci. USA, 88: $4685-4689$.

2. Boucher, D., Larcher, L-C., Gros, F., and Denoulet, P. 1994. Polyglutamylation of tubulin as a progressive regulator of in vitro interaction between the microtubule-associated protein tau and tubulin. Biochemistry, 33: 12471-12477.

3. Chu, B., Wilson, T.J., Mccune-Zierath, C., Snustad, D.P., and CARTer, J.V. 1998. Two $\beta$-tubulin genes, TUB1 and TUB8, of Arabidopsis exhibit largely nonoverlapping patterns of expression. Plant Mol. Biol., 37: 785-790.

4. Cleveland, D.W. and Sullivan, K.F. 1985. Molecular biology and genetics of tubulin. Ann. Rev. Biochem., 54: 331-365.

5. Diaz-Nido, J., Serrano, L., Lopez-Otin, C., VANDERCKhove, J., and Avila, J. 1990. Phosphorylation of a neuronal-specific beta-tubulin isotype. J. Biol. Chem., 265: 13949-13954.

6. Fosket, D.E. and MoreJohn, L.C. 1992. Structural and functional organization of tubulin. Ann. Rev. Plant Physiol. Plant Mol. Biol., 43: 201-240.
7. Gubler, U. and Hoffman, B.J. 1983. A simple and very efficient method for generating cDNA libraries. Gene, 25: 263269.

8. Hasezawa, i3. and Nagata, T. 1991. Dynamic organization of plant microt ubules at the three distinct transition points during the cell cycl: progression of synchronized tobacco BY-2 cells. Bot. Acta, 1114: 206-211.

9. Koontz, D.A. and CHor, J.H. 1993. Evidence for phosphorylation of tubulin in carrot suspension cells. Physiol. Plant., 87: 576-583.

10. LeDbeTter, M.C. and PorTer, K.R. 1970. Introduction to the fine structure of plant cells. Springer-Verlag, Berlin-Heidelberg, New York, pp.38-47.

11. LudUENA, R.F. 1998. Multiple forms of tubulin: different gene products and covalent modifications. Int. Rev. Cytol, 178: 207-275.

12. Murashige, T. and Skoog, F. 1962. A revised medium for rapid growth and bioassay with tobacco tissue culture. Physiol. Plant., 15: 4"3-497.

13. Nagata, T., Nemoto, Y., and Hasezawa, S. 1992. Tobacco BY2 cell line as the "HeLa" cell in the cell biology of higher plants. Int. Fev. Cytol., 132: 1-30.

14. Nagata, T., OKaDA, K., and TaKeBe, I. 1982, Mitotic protoplasts and their infection with tobacco mosaic virus RNA encapsulated in liposomes. Plant. Cell Rep., 1: 250-252.

15. Nishimura, M., Tanigaki, C., and Okamura, S. 1991. Changes in $\beta$-tubulin isoforms and their RNA level in synchronized tobaccol cells. Cell Struct. Funct., 16: 489-494.

16. Nogales, E., Wolf, S.G., and Downing, K.H. 1998. Structure of the $a \beta$ tubulin dimer by electron crystallography. $\mathrm{Na}$ ture, 391: 196-203.

17. Okamura, S. and Azumano, I. 1988. Primary structure of the carboxy-terminal region of a higher plant beta-tubulin. Biochem. Int., 15: 1103-1109.

18. Okamura, s., Naito, K., Sonehara, K., Ohkawa, H., Kuramori, S., Tatsuta, M., Minamizono, M., and Kataoka, T. 1997. Characterization of the carrot $\beta$-tubulin gene coding divergent isotype, $\beta$-2. Cell Struct. Funct., 22: 291-298.

19. Siflow, C.L., Oppenheimer, D.G., KopCzak, S.D., Ploense, S.E., Ludwig, S.R., HaAs, N., and Snustad, D.P. 1987. Plant tubulin genes: structure and differential expression during development. Develop. Gen., 8: 435-460.

20. Uribe, X., Torres, M.A., Capellades, M., Puigdomenéch, P., and RIgAU, J. 1998. Maize $\alpha$-tubulin genes are expressed according to ipecific patterns of cell differentiation. Plant Mol. Biol., 37: 106?-1078.

(Received for publication, March 26, 1999

and accepted, April 23, 1999) 